\title{
Virtual Water on the Southern High Plains of Texas: The Case of a Nonrenewable Blue Water Resource
}

\author{
Ryan Blake Williams ${ }^{1}$, Rashid Al-Hmoud ${ }^{2}$ \\ ${ }^{1}$ Department of Agricultural and Applied Economics, Texas Tech University, Lubbock, USA \\ ${ }^{2}$ Department of Economics, Texas Tech University, Lubbock, USA \\ Email: ryan.b.williams@ttu.edu
}

Received 30 December 2014; accepted 19 January 2015; published 22 January 2015

Copyright (C) 2015 by authors and Scientific Research Publishing Inc.

This work is licensed under the Creative Commons Attribution International License (CC BY). http://creativecommons.org/licenses/by/4.0/

cC) (i) Open Access

\begin{abstract}
This paper utilizes the virtual water concept to evaluate water usage of agricultural production in West Texas. This work evaluates the measure of virtual water, as it relates to informing water policy in a semi-arid, agriculture-intensive region, which relies upon a minimally renewable groundwater resource. The results suggest that production in the region reflects a collective effort to capture the highest value from the water resource, consistent with the virtual water philosophy, even in the absence of specific water policy toward that goal. Additionally, this work takes advantage of high resolution data to reinforce the need to calibrate virtual water calculations to account for regional differences.
\end{abstract}

\section{Keywords}

Component, Virtual Water, Water Footprint, Water Policy

\section{Introduction}

The concept of virtual water has been used to describe the means by which countries that are not water self-sufficient have overcome their water deficits. Water self-sufficiency is defined as the capacity to provide adequate freshwater resources for the domestic, industrial and food needs of a nation. Of these uses, agricultural production constitutes approximately 90 percent of a nation's demand for freshwater, on a global average [1]. The food which is imported into a country requires some quantity of water in its production, which is water that the importing nation avoids allocating to that purpose in the nation itself. It was with respect to this process that Allan [2] introduced the concept of virtual water as the water embedded in water-intensive commodities, such as food 
crops.

The acceptance of the virtual water concept has also been aided greatly by the water footprint literature [1] [3] [4] [5]. These papers focus on measuring total water consumption by individuals as consumers of specific products. To measure a water footprint, they have calculated the virtual water content of goods and services which are consumed, and aggregated those values over the average consumption patterns for individual nations. Gaining an understanding of the way in which consumption patterns impact the demand for water resources allows for improved forecasts of the global freshwater situation. This understanding also provides a framework for measuring the virtual water flows associated with particular nations or regions of interest.

The virtual water concept has garnered much attention over the past 15 years. A symposium at the 3rd World Water Forum in Kyoto received such great attention that the World Water Council hosted a web-based debate and sponsored a technical report on the issue [6]. Subsequent to that there have been multiple symposia and the development of the Water Footprint Network, which has as its mission to "promote the transition towards sustainable, fair and efficient use of fresh water resources worldwide". Utilizing the virtual water concept in domestic water policy, water-scarce countries have focused agricultural production on products with higher marginal revenue products such as tomatoes (greater than $30 \%$ of total agricultural production in Jordan) ${ }^{1}$, even though they require much more water and provide much less food. More recently, the private sector has also become interested in determining the water content of their goods and services (for example, see Patagonia's The Footprint Chronicles) ${ }^{2}$.

This work will focus on the measurement of virtual water in West Texas. Groundwater resources in the State of Texas have been the topic of much debate over the years, particularly in the Southern High Plains region. This area is of particular interest due to its limited rainfall, high agricultural utilization, and the fact that it overlies a portion of the extensive Ogallala aquifer. With little to no natural recharge to the Southern portion of the Ogallala, the freshwater resource in this area is essentially nonrenewable. Therefore, management of groundwater in this area is very active. Attempts are currently being made to limit the utilization of the aquifer in order to maintain the resource into the future.

Aldaya et al. [7] indicate that the virtual water literature has made little mention of the opportunity cost associated with the water used in production, to date. They conclude that regions with low levels of soil moisture should specialize in the production of higher valued crops. Wichelns [8] also reminds us that the opportunity cost of surface water and groundwater isn't necessarily greater than that of water existing in the soil. In particular, surface water and groundwater have alternative competing uses in any time period. Additionally, there are many resources which contribute to the production of a good or service and the opportunity cost associated with that production. This research serves, in part, to highlight the relationship between the virtual water methodology and the opportunity cost of water use from nonrenewable groundwater sources. We contend that the distinction between groundwater and soil moisture is important in a time-varying sense, as the current use of a groundwater resource removes the possibility of its use in subsequent time periods.

Due to the unique hydrologic, economic and legal situations in this region of Texas, there is an opportunity to evaluate the concept of virtual water over a highly homogeneous area. We will provide detailed measurement of the water resources required for various crops across this region, and demonstrate the degree to which these measurements vary across space and time. Aldaya et al. [9] demonstrate that the use of regional data that accounts for higher resolution climatic data and local producer behavior yields significantly different virtual water values than those obtained from lower resolution climate data and avoids region-specific production practices. By observing the variations in virtual water over time, accounting for the water use practices of local producers, and applying a coefficient to account for the specific irrigation effectiveness of the irrigation technologies in use in the region, this work suggests that there are potential gains to be made in applying the virtual water methodology to regional water issues.

The purpose of this research is to demonstrate the degree to which quantification of virtual water varies across space and time, utilizing high resolution data. Accuracy of the measurement will be tested against the measured usage of the groundwater resource over the study area. Additionally, we provide results which can help to inform water policy in West Texas. The paper will proceed in the following manner. Section 2 will outline the methodology of quantifying virtual water and subsequent water use measurements for the study area. In section 3 , the specific data which will be used to assess the variations in virtual water measurements will be described in

\footnotetext{
${ }^{1}$ Source: IPU Jordan.

${ }^{2}$ Available at http://www.patagonia.com/us/footprint/index.jsp?src=vuca0045.
} 
detail. Section 4 presents the findings of this research, and section 5 presents our conclusions and directions for future research.

\section{Methodology}

The specific water use (SWU) of a crop may be calculated as the volume of water necessary to produce a tonne of the commodity [10] [11]. Specifically, the SWU of a particular crop is calculated as SWU $=\mathrm{SWU} /$ Yield, where CWU is the crop water usage, and is a function of the crop water requirement (CWR).

It is important to note that the use of CWR in obtaining values for SWU assumes that the amount of water required by the crop is the amount that producers actually use. However, it is possible that the freshwater resource used up in the production process either exceeds the crop water requirement, or in many cases, may be significantly less than the CWR.

Following Chapagain and Orr [12] and Chapagain et al. [5], we will account for the percent irrigation effectiveness. The adoption of irrigation technology varies greatly by region, and is a function of crop, the cost of implementation, soil types, slope of land, and how the water resource is acquired. According to the Texas Water Development Board [13], approximately $95 \%$ of irrigated cropland in the study area were irrigated using some form of sprinkler technology. We obtain irrigation effectiveness from Amosson et al. [14] for each of the technologies which allows us to estimate an average irrigation effectiveness of $88 \%$ for the area of study, which we apply to the calculations here. Blue water needs of the crop are multiplied by a factor of 1.136 to account for the regional irrigation effectiveness.

In arid and semi-arid regions there has been a movement away from full-irrigation of crops toward the practice of deficit irrigation. Deficit irrigation is defined as the application of less than 100 percent of the CWR for a given crop. This practice results in reduced yields, as compared to full-irrigation practices, but a potentially significant savings in water resources. We will assume in our calculations that the typical producer in the study area applies water under a $75 \%$ deficit irrigation protocol, or $\mathrm{CWU}_{i C}=0.75\left(\mathrm{CWR}_{C}\right)$.

Allan [15] suggests that it is the water that exists in the soil profiles of the world that are ultimately the key to providing sufficient agricultural production for growing worldwide demand. In evaluating the total water that is involved in the production of a given commodity it is informative to determine the proportion of that water which is applied via irrigation. Water which is applied through irrigation must come from either groundwater or surface water sources. These include rivers, lakes, streams, and aquifers. Water from these sources is termed blue water. The other type of water which is involved in the production of agricultural commodities is that water which exists in the soil profile, and is accessible to a growing crop's root system. This moisture which exists in the soil is termed green water [16].

Chapagain et al. [5] have separated virtual water into its blue and green components. Our research is especially concerned with this concept as blue water in the study region has a relatively high opportunity cost compared to its green water counterpart. In the case of a nonrenewable, or minimally renewable, blue water resource such as the Southern portion of the Ogallala aquifer, its use precludes future use. Therefore a clear understanding of the blue and green components of SWU has important policy implications.

Following the methodology employed by Chapagain and Orr [12], we separate virtual water into its blue and green components. We evaluate the SWU for a crop as the summation of the specific water use of a crop resulting from effective rainfall (green) and the specific water use from irrigation (blue). Formally,

$$
\mathrm{SWU}_{c}=\mathrm{SWU}_{g}+\mathrm{SWU}_{b}=\frac{\mathrm{SWU}_{g}}{\text { Yield }}+\frac{\mathrm{SWU}_{b}}{\text { Yield }}
$$

where $\mathrm{CWU}_{g}$ is effective rainfall and $\mathrm{CWU}_{b}$ is calculated as the amount of water beyond effective rainfall that must be applied to meet the total CWR.

\section{Data}

The data used here has been selected for the purpose of providing the most accurate quantification of the virtual water content of commodities being produced within the High Plains Underground Water Conservation District (HPUWCD) No. 1 of the state of Texas. This region is unique for a couple of reasons, and is therefore well suited to this analysis.

First, the area under consideration is relatively flat, exhibiting only minor elevation change across the region 
(a difference of approximately 300 meters).This characteristic provides for homogeneous production techniques as well as very little variation in climate. Second, the area is consistently semi-arid, receiving about 48 centimeters of precipitation per year on average. Third, the area overlies the Southern portion of the Ogallala aquifer. This groundwater source provides the region with the freshwater resources necessary to support agricultural production, but that production has resulted in a significant decline in the resource. In addition to being a relatively homogeneous area in terms of topography, climate, and access to groundwater, the water users within these counties are subject to the same water policy and oversight by the HPUWCD.

The CWRs for the relevant crops within the HPUWCD were obtained for a ten year time period (1997-2006) to allow for observation across time. For subsequent studies an extension of this data would be useful to evaluate the effect of changes in technology, climate, and resource availability on specific water use. The CWR for each crop is obtained by evaluating the evapotranspiration (ET) of each crop in each time period. The ET data is taken from the Texas High Plains Evapotranspiration (TXHPET) Network ${ }^{3}$. The TXHPET Network provides daily data for the reference ET as well as all relevant crop-specific values at various monitoring sites across the region.

Yield data was obtained at the county level from the USDA NASS data $\operatorname{set}^{4}$. The six primary crops of the study region are upland cotton, corn for silage, grain sorghum for silage, wheat for silage, soybeans, and peanuts. Crop yield data was collected for the same ten year period as the CWR calculations, 1997-2006. Additionally, cattle data were acquired for the study area so that the water needs of the feed cattle industry in the region could be evaluated.

The final set of data necessary to evaluate the water usage in the production of crops within the HPUWCD is daily precipitation data. Precipitation data is used to calculate effective rainfall and green water. Precipitation data is taken from the TXHPET Network in an effort to utilize the same meteorological experiences as those that determined the CWR of each crop. Effective rainfall is calculated by importing the daily precipitation data into CROPWAT $8.0^{5}$. Following Chapagain and Hoekstra [17] and Chapagain et al. [5], the USDA Soil Conservation Service (SCS) method was used within CROPWAT to obtain effective rainfall values. Green water is then calculated as the effective rainfall that the crop utilizes to meet ET.

Finally, the drawdown of the aquifer over the study period is acquired so that actual usage can be compared with our estimates. The change in water storage in acre feet is obtained from the Texas Tech University Center for Geospatial Technology ${ }^{6}$, and is a result of extensive mapping of actual well observations.

\section{Results}

This research aims to evaluate agricultural production on the southern High Plains of Texas using with respect to the virtual water concept. In particular, we quantify the water content of the six primary field crops, decompose the water content into its blue and green components, and investigate the virtual water trade flows associated with the regional cattle industry. Additionally, we compare our estimates of water usage in the region with observed withdrawals from the groundwater resource. This will inform the degree to which future estimates should be scaled to reflect actual water usage in West Texas.

First, we present values for SWU over a 10-year period. Knowing the variations in SWU will lend itself to determining the value of water in the production of these crops, holding all else constant. Policy makers looking to maximize the efficiency of the water resource in terms of its value should look to this measure. Knowledge of the amount of water necessary to produce a tonne of a specific crop allows for valuing the allocation of water in its varied uses by dividing the SWU by the dollars per ton received for the commodity.

Second, because it is ultimately the groundwater resource that is of concern and not precipitation, we decompose SWU into its blue and green components. Using the SWU from blue water we present the value of an acre-inch of water applied to each of the six crops in the region. We also present, as a comparison, the value per acre-inch of blue water when comparing non-irrigated cotton yields to irrigated cotton yields.

Third, we evaluate the water usage of the cattle industry in the study area. The virtual water trade associated with the cattle industry demonstrates the usefulness of evaluating virtual water trade flows. It also serves as an indication of the potential for virtual water calculations to inform water policy. In particular, we may gain a bet-

\footnotetext{
${ }^{3}$ Retrieved July 2008 from http://txhighplainset.tamu.edu/index.jsp.

${ }^{4}$ Retrieved July 2008 from http://www.nass.usda.gov/.

${ }^{5}$ Available at $\mathrm{http} / / / \mathrm{www}$. fao.org/nr/water/infores_databases_cropwat.html.

${ }^{6}$ Available at http://www.gis.ttu.edu/center/Ogallala/Index.html .
} 
ter understanding of which crops should be produced locally and how the import of other crops from another production region can lead to increased returns on the scarce local water resource.

Finally, we evaluate the accuracy of our measurement against the observed depletion of the aquifer over the ten years of our study period. These findings will help to inform future modifications to the calculation of virtual water in the area in order to increase accuracy and improve its efficacy as a policy tool.

\subsection{Specific Water Use}

We obtain the SWU of each of the six relevant crops in each of the 15 counties in the region, over the 19972006 time period, are calculated. We find that there is significant variation across the region over time. For irrigated cotton, the most prevalent crop, there is a difference of 4300 cubic meters per tonne for SWU between two counties in year 2000 . That variation represents $84 \%$ of the average SWU for the study period. Provided in Table 1 is the average SWU for all crops over the study period.

\subsection{Blue and Green SWU}

Understanding the makeup of the SWU in terms of its blue and green components is especially important here because this region relies on the limitedly-renewable groundwater resources, contained in the Southern portion of the Ogallala aquifer, for agricultural production. With limited rainfall, water pumped from the aquifer accounts for a relatively large percentage of the total water needed by locally produced crops. Additionally, as a limitedly-renewable resource, the external costs associated with its use include not only current alternate uses, but the lost future use of the resource as well.

In order to measure the amount of irrigation necessary to bring a crop to harvest we must first obtain values for effective rainfall. These values vary greatly from year to year as the amount of precipitation varies. Because the producer is capable of substituting precipitation for irrigation, years with above normal rainfall place less stress on the groundwater resource. This allows the individual producer (and the collective agricultural community relying on the aquifer) to extend their planning horizon as more of the resource remains in situ.

Having obtained daily effective rainfall values for the region we are able to determine the portion of the CWR that is met by effective rainfall. As mentioned in Section 2, we have assumed that producers operate under a 75\% deficit irrigation protocol. The amount of blue water needed by the crop is then calculated as the difference between meeting $75 \%$ of the CWR and the quantity of effective rainfall. Multiplying this value by 1.136 to account for the assumed $88 \%$ irrigation effectiveness yields the total blue water usage. We then use effective rainfall, blue water use, and crop yield to evaluate the portion of the SWU of each crop that is attributable to green and blue water. Table 2 presents $\mathrm{SWU}_{g}$ and Table 3 presents $\mathrm{CWU}_{b}$.

While it is informative to know the source of water used by the crop, as well as the amount of water that is necessary to obtain a particular amount of each crop, these measures don't provide the water policy maker (or producer) with the necessary information to inform decisions. However, by applying the market price for a ton of each commodity we are able to determine the amount of revenue resulting from the application of the blue water resource across crops (see Table 4). It is important that this information alone isn't used to inform water

Table 1. Average SWU (cubic meters per tonne).

\begin{tabular}{ccccccc}
\hline Year & Corn & Cotton & Sorghum & Wheat & Peanut & Soybean \\
\hline 1997 & 650 & 4760 & 847 & NaN & 2415 & 1966 \\
1998 & 1199 & 5425 & 942 & 1086 & 1098 & 1992 \\
1999 & 748 & 6406 & 906 & 1084 & 919 & 1828 \\
2000 & 765 & 7344 & 1099 & 1281 & 1166 & 1983 \\
2001 & 784 & 5521 & 1062 & 924 & 1114 & 1738 \\
2002 & 758 & 4351 & 1024 & 1559 & 1299 & 1763 \\
2003 & 720 & 4865 & 968 & 1219 & 1162 & NaN \\
2004 & 609 & 4939 & 1290 & 1059 & 2075 & NaN \\
2005 & 596 & 3832 & 821 & 870 & 1376 & 1226 \\
2006 & 722 & 3638 & 923 & 1506 & NaN & NaN \\
\hline
\end{tabular}


Table 2. Average SWU from effective rainfall (cubic meters/tonne).

\begin{tabular}{ccccccc}
\hline Year & Corn & Cotton & Sorghum & Wheat & Peanut & Soybean \\
\hline 1997 & 363.2 & 3755.6 & 599.4 & 960.9 & 2087.6 & 1568.3 \\
1998 & 277.3 & 1689.5 & 314.5 & 458.1 & 521.0 & 1076.5 \\
1999 & 497.7 & 3105.8 & 487.7 & 477.9 & 713.3 & 1164.4 \\
2000 & 214.3 & 2854.8 & 432.2 & 428.4 & 884.2 & 950.4 \\
2001 & 367.1 & 2779.7 & 582.1 & 643.6 & 826.4 & 1457.2 \\
2002 & 265.2 & 2334.4 & 581.7 & 417.9 & 919.7 & 850.8 \\
2003 & 214.8 & 1764.8 & 367.6 & 500.9 & 631.6 & 1043.8 \\
2004 & 410.9 & 4616.7 & 1226.2 & 797.1 & 1978.0 & $\mathrm{NaN}$ \\
2005 & 290.3 & 2407.8 & 549.7 & 779.8 & 725.9 & 594.9 \\
2006 & 292.1 & 1846.9 & 494.2 & 484.8 & $\mathrm{NaN}$ & $\mathrm{NaN}$ \\
\hline
\end{tabular}

Table 3. Average SWU from blue water (cubic meters/tonne).

\begin{tabular}{ccccccc}
\hline Year & Corn & Cotton & Sorghum & Wheat & Peanut & Soybean \\
\hline 1997 & 286.6 & 1004.7 & 247.7 & NaN & 327.4 & 397.3 \\
1998 & 921.8 & 3735.2 & 628.0 & 627.5 & 454.3 & 917.0 \\
1999 & 250.4 & 3300.5 & 418.4 & 559.3 & 126.0 & 381.4 \\
2000 & 550.3 & 4488.8 & 666.5 & 850.8 & 437.9 & 1140.7 \\
2001 & 416.9 & 2740.8 & 480.0 & 276.3 & 361.1 & 281.0 \\
2002 & 492.8 & 2016.4 & 442.0 & 1148.5 & 379.2 & 868.0 \\
2003 & 505.3 & 3100.7 & 600.0 & 721.1 & 530.4 & $\mathrm{NaN}$ \\
2004 & 198.4 & 419.6 & 64.1 & 249.9 & 96.8 & $\mathrm{NaN}$ \\
2005 & 305.6 & 1424.6 & 270.9 & 91.3 & 649.8 & 631.2 \\
2006 & 430.1 & 1791.0 & 428.6 & 1017.0 & $\mathrm{NaN}$ & $\mathrm{NaN}$ \\
\hline
\end{tabular}

Table 4. Value of blue water usage (\$USA (yr 2000)/cubic meter).

\begin{tabular}{|c|c|c|c|c|c|c|}
\hline Year & Corn & Cotton & Sorghum & Wheat & Peanut & Soybean \\
\hline 1997 & $\$ 0.33$ & $\$ 1.16$ & $\$ 0.33$ & $\mathrm{NaN}$ & $\$ 1.44$ & $\$ 0.52$ \\
\hline 1998 & $\$ 0.09$ & $\$ 0.30$ & $\$ 0.12$ & $\$ 0.14$ & $\$ 1.08$ & $\$ 0.16$ \\
\hline 1999 & $\$ 0.31$ & $\$ 0.26$ & $\$ 0.15$ & $\$ 0.14$ & $\$ 3.40$ & $\$ 0.38$ \\
\hline 2000 & $\$ 0.16$ & $\$ 0.23$ & $\$ 0.11$ & $\$ 0.11$ & $\$ 1.24$ & $\$ 0.14$ \\
\hline 2001 & $\$ 0.23$ & $\$ 0.24$ & $\$ 0.18$ & $\$ 0.39$ & $\$ 1.45$ & $\$ 0.63$ \\
\hline 2002 & $\$ 0.22$ & $\$ 0.47$ & $\$ 0.22$ & $\$ 0.10$ & $\$ 1.14$ & $\$ 0.23$ \\
\hline 2003 & $\$ 0.23$ & $\$ 0.46$ & $\$ 0.17$ & $\$ 0.17$ & $\$ 0.91$ & $\mathrm{NaN}$ \\
\hline 2004 & $\$ 0.60$ & $\$ 2.46$ & $\$ 1.60$ & $\$ 0.57$ & $\$ 5.10$ & $\mathrm{NaN}$ \\
\hline 2005 & $\$ 0.39$ & $\$ 0.88$ & $\$ 0.39$ & $\$ 1.70$ & $\$ 0.75$ & $\$ 0.39$ \\
\hline 2006 & $\$ 0.38$ & $\$ 0.74$ & $\$ 0.35$ & $\$ 0.21$ & $\mathrm{NaN}$ & $\mathrm{NaN}$ \\
\hline mean & $\$ 0.29$ & $\$ 0.72$ & $\$ 0.36$ & $\$ 0.39$ & $\$ 1.84$ & $\$ 0.35$ \\
\hline
\end{tabular}


policy, as water is not the only factor of production. But this does provide valuable insight into where the highest-valued use of the water resource might occur.

The values presented in Table 4 suggest that the best use of the blue water resource over this ten year time period is in the production of peanuts. However, peanuts are produced in a relatively small area of the region. Their production is limited by the need for sandy soil and a minimum of two years crop rotation. Of the other crops, which are more homogeneous in their production, cotton yields the greatest return on the water resource in the region. If the focus of the policy maker in this region were to garner the greatest revenues from the scarce water resource when used for the production of agricultural commodities, then policy encouraging the production of cotton should be encouraged.

As a comparison to the blue water SWU values provided above, we compare the value received from irrigated cotton in the region to the value of dryland cotton production (see Table 5). The estimated value of blue water should be similar, but differences in the production technologies of the two crops yield some variation in our valuation. It is clear from either method of calculating the value of blue water that the use of the groundwater resource yields increased revenues for the producing region. However, we may ask whether these increased revenues are an appropriate use of a scarce water resource. In particular, it is worth noting that, on average, irrigation of cotton results in an increase of $\$ 0.19$ per cubic meter of water across the study area between 1997 and 2006. Referring back to Table 4, we find that blue water use for cotton production results in an average of $\$ 0.72$ per cubic meter. As a comparison, citizens of the city of Lubbock, TX (the largest population density in the region) pay between $\$ 0.71$ and $\$ 1.57$ per cubic meter of residential water use ${ }^{7}$. These rates should reflect a lower bound on the value that citizens place on water as their willingness to pay will exceed or meet these values over the range of consumption in the market.

These results suggest that water policy in the region should emphasize maintaining the water resource for domestic use in the future while simultaneously promoting the production of high-valued rain fed or minimal irrigation crops. Given the role of agricultural production in the economy of the region, a perfect balance is likely difficult to achieve.

\subsection{Virtual Water and the Cattle Industry}

The region is also home to a large number of firms in the cattle and dairy industries. These industries rely heavily on feed for their livestock, making it a water intensive production process. Water usage for the production of livestock can be divided into two primary categories. First, direct water usage is the water that is required by the animals on site, which includes water for drinking and wastewater. Direct water in the region is obtained from the aquifer. The second form of water usage is indirect, which is comprised of the water content of the feedstock that the animals require. This water is sourced from the aquifer when it comes from feedstock produced locally. However, when there is a higher valued use of the resource (such as cotton production), it is preferable for the

Table 5. Dryland and irrigated cotton comparison.

\begin{tabular}{|c|c|c|c|c|c|c|c|}
\hline \multirow{2}{*}{ Year } & Dry & Irr & Diff & \multirow{2}{*}{$\begin{array}{c}\text { \$/tonne } \\
\text { cotton }\end{array}$} & \multirow{2}{*}{$\begin{array}{c}\text { "Value" } \\
\text { of irrigation }\end{array}$} & \multirow{2}{*}{$\begin{array}{c}\text { Blue water } \\
\left(\mathrm{m}^{3} / \mathrm{ha}\right)\end{array}$} & \multirow{2}{*}{$\begin{array}{l}\text { "Value" } \\
\text { per } \mathrm{m}^{3}\end{array}$} \\
\hline & \multicolumn{3}{|c|}{ (tonne/hectare) } & & & & \\
\hline 1997 & 0.462 & 0.712 & 0.250 & $\$ 1320.84$ & $\$ 330.02$ & 1584 & $\$ 0.21$ \\
\hline 1998 & 0.325 & 0.759 & 0.434 & $\$ 1259.25$ & $\$ 546.94$ & 4117 & $\$ 0.13$ \\
\hline 1999 & 0.440 & 0.643 & 0.203 & $\$ 1034.26$ & $\$ 209.54$ & 2385 & $\$ 0.09$ \\
\hline 2000 & 0.244 & 0.548 & 0.303 & $\$ 1422.17$ & $\$ 431.45$ & 3738 & $\$ 0.12$ \\
\hline 2001 & 0.340 & 0.739 & 0.400 & $\$ 949.75$ & $\$ 379.76$ & 3029 & $\$ 0.13$ \\
\hline 2002 & 0.306 & 0.882 & 0.577 & $\$ 656.79$ & $\$ 378.80$ & 2899 & $\$ 0.13$ \\
\hline 2003 & 0.263 & 0.752 & 0.489 & $\$ 1011.92$ & $\$ 494.90$ & 3805 & $\$ 0.13$ \\
\hline 2004 & 0.661 & 0.963 & 0.302 & $\$ 853.28$ & $\$ 257.28$ & 537 & $\$ 0.48$ \\
\hline 2005 & 0.722 & 1.121 & 0.398 & $\$ 1,123.01$ & $\$ 447.37$ & 2145 & $\$ 0.21$ \\
\hline 2006 & 0.329 & 0.991 & 0.662 & $\$ 1169.96$ & $\$ 774.56$ & 3045 & $\$ 0.25$ \\
\hline
\end{tabular}

${ }^{7}$ Obtained 10/19/2011 from

http:/www.mylubbock.us/departmental-websites/departments/water-department/top-navigation-menu-items/services/bill-calculation. 
Table 6. Cattle industry water usage (million cubic meters).

\begin{tabular}{cccccccc}
\hline Year & Total water & Direct water & Indirect water & Local indirect & Local total & Imported & Imports/total \\
\hline 1997 & 1.762 & 39 & 1.723 & 631 & 670 & 1.091 & 0.62 \\
1998 & 5.210 & 37 & 5.173 & 1,354 & 1.392 & 3.818 & 0.73 \\
1999 & 1.467 & 34 & 1.434 & 542 & 575 & 892 & 0.61 \\
2000 & 3.169 & 35 & 3.134 & 745 & 781 & 2.389 & 0.75 \\
2001 & 2.415 & 36 & 2.379 & 577 & 612 & 1.802 & 0.75 \\
2002 & 2.804 & 36 & 2.768 & 614 & 650 & 2.154 & 0.77 \\
2003 & 2.975 & 36 & 2.938 & 777 & 814 & 2.161 & 0.73 \\
2004 & 1.139 & 38 & 1.101 & 193 & 232 & 908 & 0.80 \\
2005 & 1.789 & 37 & 1.753 & 407 & 444 & 1.346 & 0.75 \\
2006 & 2.940 & 43 & 2.897 & 386 & 428 & 2.511 & 0.85 \\
Mean & 2.567 & 37 & 2.530 & 623 & 660 & 1.907 & 0.74 \\
\hline
\end{tabular}

water embodied in the feedstock to be imported from other regions. In Table 6 we present the water used by cattle producers in the region. Of primary interest is the share of the total water needs being imported in the form of indirect water. The water-scarce producing region has allocated the resource to its highest-valued use while importing the more water-intensive, lower-valued, dry grains. These findings support the proposition by Wichelns [18] that the optimal production decision, given scarce water resources, will often resemble policy that has been informed by the virtual water concept. Namely, that the region should produce those agricultural commodities that represent a high value per unit of water while importing lower valued commodities.

\subsection{Assessment of Virtual Water Measure Accuracy}

The previous calculations have provided a picture of the water usage in the Southern High Plains of West Texas by utilizing the accepted virtual water measure. Here, we present a comparison of the aggregation of our estimates to the observed change in water available in the aquifer. If we are to continue to use virtual water calculations to assist in forming water policy, it is important that they are an accurate reflection of local water usage.

In order to compare our estimates of water usage with the change in the volume of water in the aquifer, we must first account for the volume of water that is re-entering the aquifer on an annual basis through recharge. Mullican III et al. [19] reviewed numerous studies of recharge in the area and found that the majority of those studies place the natural recharge rate at between 1.27 and 7.62 centimeters annually, depending on the precise location of the study. Based upon those results we have assumed natural recharge of 2.54 centimeters annually. Our blue water estimates have assumed an $88 \%$ irrigation effectiveness and $75 \%$ deficit irrigation protocol. However, it is also necessary to adjust our estimates of total water usage to account for uses outside of agricultural commodity production. Amosson et al. [20] find that typical water usage by the agricultural commodity production sector accounts for $93.25 \%$ of all water usage in the region. We have therefore increased our estimates of water usage to account for this additional demand on the water in the aquifer. The results of these calculations are presented in Table 7.

We find that, on average, we have overestimated the water usage in the region by 345 million cubic meters per year. The average number of irrigated hectares over this time period is 803,459 , which implies an overestimate of 4.3 centimeters of water applied on average. This discrepancy ranges from $7 \%$ to $108 \%$ of estimated blue water usage per acre. While the calculations provided throughout this work are still quite informative, and may be used to help inform water policy, it should be noted that this methodology could further benefit from increased resolution of the data.

\section{Conclusions}

In this work we have evaluated the water usage in the agricultural commodity production sector of the Southern High Plains of Texas by employing the virtual water methodology. CWR is used to calculate SWU. We present 
Table 7. Estimated and observed water usage (million cubic meters).

\begin{tabular}{|c|c|c|c|c|c|c|}
\hline Year & Storage & $\Delta$ Storage & $\Delta$ Storage less recharge & Blue water use & Total water & Estimate less observed \\
\hline 1999 & 104,666 & $(2.867)$ & - & - & - & - \\
\hline 2000 & 103,975 & $(691)$ & $(1.515)$ & 2.200 & 2.359 & 844 \\
\hline 2001 & 102,025 & $(1.950)$ & $(2.775)$ & 3.153 & 3.381 & 606 \\
\hline 2002 & 100,516 & $(1.509)$ & $(2.334)$ & 2.080 & 2.231 & (103) \\
\hline 2003 & 99,357 & $(1.160)$ & $(1.984)$ & 2.390 & 2.563 & 578 \\
\hline 2004 & 97,504 & (1.853) & $(2.678)$ & 2.701 & 2.896 & 218 \\
\hline 2005 & 97,082 & $(422)$ & $(1.247)$ & 501 & 538 & (709) \\
\hline 2006 & 96,921 & (160) & $(985)$ & 1.416 & 1.519 & 533 \\
\hline 2007 & 96,296 & $(625)$ & $(1.450)$ & 2.094 & 2.246 & 796 \\
\hline
\end{tabular}

SWU values, because the CWR data are misleading (stated later in this paragraph). This result reinforces the need to obtain the highest resolution data possible when conducting virtual water research. Additionally, if the CWR were to be used to inform policy, it would suggest that the two most prevalent crops, cotton and corn, should not be produced. Such a policy decision would result in lower returns on the water resource, which is why we have presented the preferred measure of SWU.

We then provided the SWU of the relevant crops, and evaluated the blue water and green water composition of SWU. We find that local producers are already producing the crops which yield the greatest value from the water resource. This result isn't surprising given that the costs of other inputs in the production process are quite similar across the crops produced in the region.

Finally, we presented data on water usage by the cattle and dairy industries in the region. We found that the direct water needs were being met with the local water resource, but that the majority of water-intensive feed grains were being imported from other producing regions of the United States. Through the import of the water contained in the feed grains, local cattle producers are able to maximize the return on the local water resource. Given this, those responsible for water policy in the area should encourage similar behavior if conservation and return on the water resource continue to be the goals.

Future research in this area should evaluate the differential impact that trade of water-intensive goods has on producing regions. The negative externalities related to agricultural production are typically not captured in the price of the commodity. However, the virtual water concept may provide an opportunity to begin to value these third-party costs. During the production process there are multiple chemicals (nitrogen fertilizers, herbicides and pesticides) applied which must ultimately be dissolved by the water resource. Additionally, the use of a nonrenewable underground water resource for irrigation in one period necessarily reduces the available resource in all subsequent periods. Quantification of these negative externalities in terms of water will result in an increased measure of virtual water and may help to inform policy in ways that the price mechanism has failed previously.

\section{References}

[1] Hoekstra, A.Y. and Chapagain, A.K. (2007) Water Footprints of Nations: Water Use by People as a Function of Their Consumption Pattern. Water Resources Management, 21, 35-48. http://dx.doi.org/10.1007/s11269-006-9039-x

[2] Allan, J.A. (1998) Moving Water to Satisfy Uneven Global Needs: "Trading" Water as an Alternative to Engineering It. ICID Journal: International Council on Irrigation and Development, 47, 1-8.

[3] Hoekstra, A.Y. and Chapagain, A.K. (2007) The Water Footprints of Morocco and the Netherlands: Global Water Use as a Result of Domestic Consumption of Agricultural Commodities. Ecological Economics, 64, 143-151. http://dx.doi.org/10.1016/j.ecolecon.2007.02.023

[4] Chapagain, A.K. and Hoekstra, A.Y. (2007) The Water Footprint of Coffee and Tea Consumption in the Netherlands. Ecological Economics, 64, 109-118. http://dx.doi.org/10.1016/j.ecolecon.2007.02.022

[5] Chapagain, A.K., Hoekstra, A.Y., Savenije, H.H.G. and Gautam, R. (2006) The Water Footprint of Cotton Consumption: An Assessment of the Impact of Worldwide Consumption of Cotton Products on the Water Resources in the Cotton Producing Countries. Ecological Economics, 60, 186-203. http://dx.doi.org/10.1016/j.ecolecon.2005.11.027 
[6] World Water Council (2004) E-Conference Synthesis: Virtual Water Trade-Conscious Choices. Marseille, France.

[7] Aldaya, M.M., Allan, J.A. and Hoekstra, A.Y. (2010) Strategic Importance of Green Water in International Crop Trade. Ecological Economics, 69, 887-894. http://dx.doi.org/10.1016/j.ecolecon.2009.11.001

[8] Wichelns, D. (2010) Virtual Water: A Helpful Perspective, But Not a Sufficient Policy Criterion. Water Resources Management, 24, 2203-2219. http://dx.doi.org/10.1007/s11269-009-9547-6

[9] Aldaya, M.M., Garrido, A., Llamas, M.R., Varela-Ortega, C., Novo, P. and Casado, R.R. (2009) Water Footprint and Virtual Water Trade in Spain. In: Garrido, A. and Llamas, M.R., Eds., Water Policy in Spain, CRC Press, Leiden, 4959.

[10] Velazquez, E. (2007) Water Trade in Andalusia. Virtual Water: An Alternative Way to Manage Water Use. Ecological Economics, 63, 201-208. http://dx.doi.org/10.1016/j.ecolecon.2006.10.023

[11] Hoekstra, A.Y. and Hung, P.Q. (2002) Virtual Water Trade: A Quantification of Virtual Water Flows between Nations in Relation to Crop Trade. IHE, Delft, The Netherlands.

[12] Chapagain, A.K. and Orr, S. (2009) An Improved Water Footprint Methodology Linking Global Consumption to Local Water Resources: A Case of Spanish Tomatoes. Journal of Environmental Management, 90, 1219-1228. http://dx.doi.org/10.1016/j.jenvman.2008.06.006

[13] Texas Water Development Board (2001) Report 347: Surveys of Irrigation in Texas 1958, 1964, 1969, 1974, 1979, $1984,1989,1994$, and 2000. http://www.twdb.texas.gov/publications/reports/numbered reports/doc/R347/Report347.asp

[14] Amosson, S., New, L., Almas, L., Bretz, F. and Marek, T. (2001) Economics of Irrigation Systems. Texas AgriLife Extension, Texas A\&M System, College Station.

[15] Allan, J.A. (1997) "Virtual Water": A Long Term Solution for Water Short Middle Eastern Economies. British Association Festival of Science, Water and Development Session, University of Leeds, London.

[16] Falkenmark, M. (1995) Land-Water Linkages: A Synopsis. In: Mather, T., Ed., Land and Water Bulletin: Land and Water Integration and River Basin Management, Vol. 1, Food and Agriculture Organization (FAO) of the United Nations, Rome, 15-16.

[17] Chapagain, A.K. and Hoekstra, A.Y. (2011) The Blue, Green, and Grey Water Footprint of Rice from Production and Consumption Perspectives. Ecological Economics, 70, 749-758. http://dx.doi.org/10.1016/j.ecolecon.2010.11.012

[18] Wichelns, D. (2005) The Virtual Water Metaphor Enhances Policy Discussions Regarding Scarce Resources. Water International, 30, 428-437. http://dx.doi.org/10.1080/02508060508691887

[19] Mullican III, W., Johns, N. and Fryar, A. (1997) Playas and Recharge of the Ogallala Aquifer on the Southern High Plains of Texas-An Examination Using Numerical Techniques. Bureau of Economics Geology, The University of Texas at Austin, Austin.

[20] Amosson, S., Guerrero, B., Smith, J., Johnson, J., Johnson, P., Weinheimer, J., Almas, L. and Roberts, J. (2010) Water Use by Confined Livestock Operations and Ethanol Plants in the Texas High Plains. Texas AgriLife Extension Service, Texas Tech University, and West Texas A\&M University. 
Scientific Research Publishing (SCIRP) is one of the largest Open Access journal publishers. It is currently publishing more than 200 open access, online, peer-reviewed journals covering a wide range of academic disciplines. SCIRP serves the worldwide academic communities and contributes to the progress and application of science with its publication.

Other selected journals from SCIRP are listed as below. Submit your manuscript to us via either submit@scirp.org or Online Submission Portal.
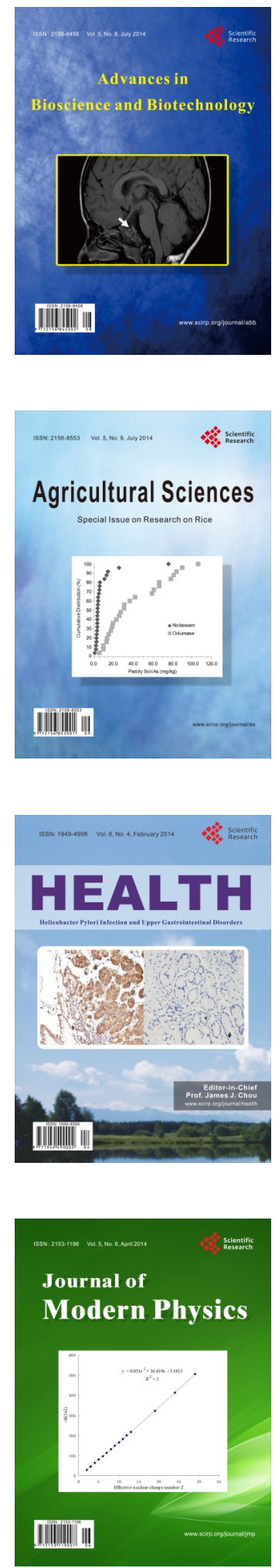
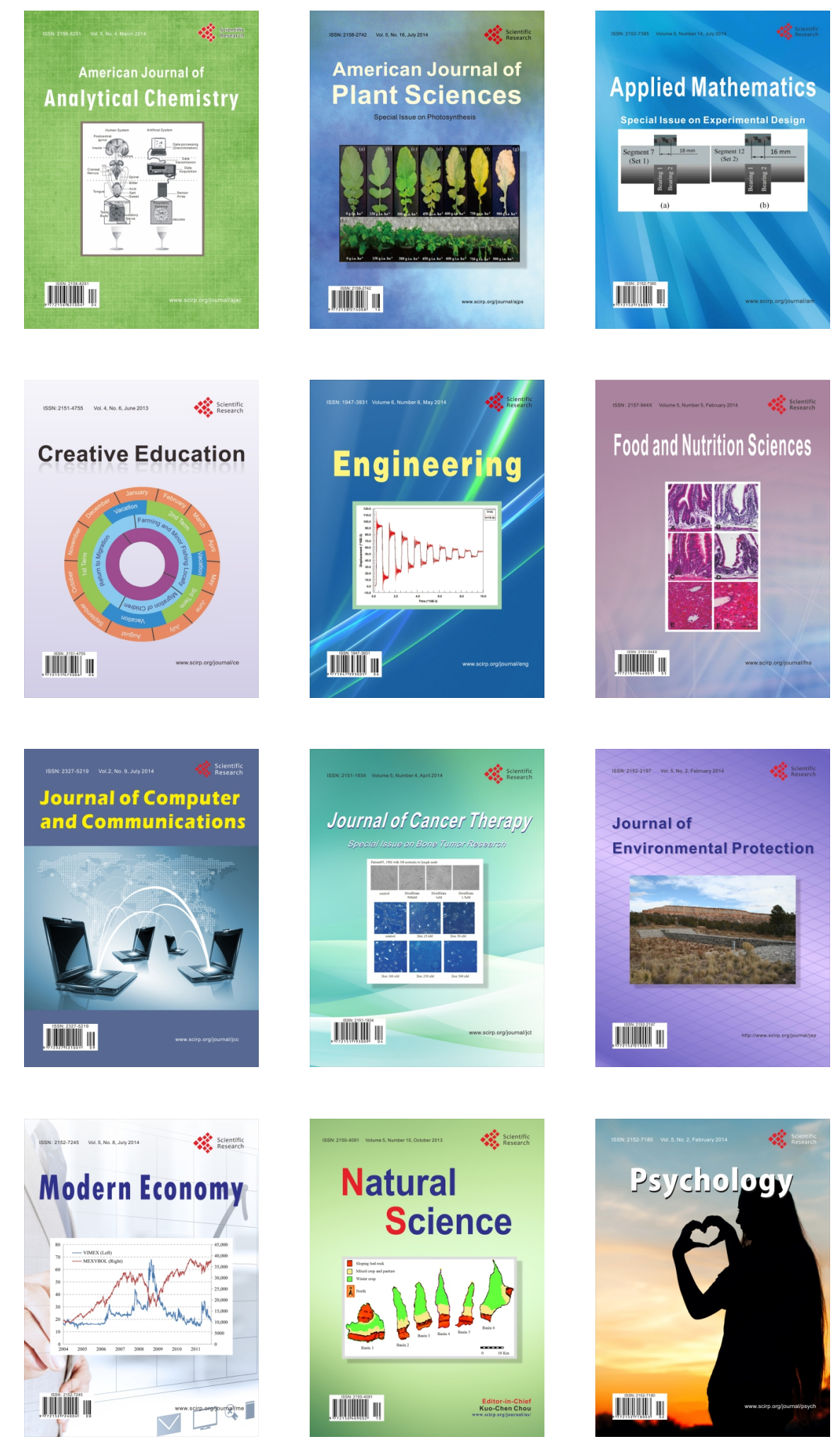